ARTICLE

Received 4 May 2013 | Accepted 23 Oct 2013 | Published 18 Dec 2013 DOl: 10.1038/ncomms3817

\title{
Direct observation of the oxygenated species during oxygen reduction on a platinum fuel cell cathode
}

Hernan Sanchez Casalongue ${ }^{1,2}$, Sarp Kaya ${ }^{1,2}$, Venkatasubramanian Viswanathan ${ }^{1,3}$, Daniel J. Miller ${ }^{1}$, Daniel Friebel ${ }^{1,2}$, Heine A. Hansen ${ }^{1,3}$, Jens K. Nørskov ${ }^{1,3}$, Anders Nilsson ${ }^{1,2,4}$ \& Hirohito Ogasawara ${ }^{1,4}$

The performance of polymer electrolyte membrane fuel cells is limited by the reduction at the cathode of various oxygenated intermediates in the four-electron pathway of the oxygen reduction reaction. Here we use ambient pressure $X$-ray photoelectron spectroscopy, and directly probe the correlation between the adsorbed species on the surface and the electrochemical potential. We demonstrate that, during the oxygen reduction reaction, hydroxyl intermediates on the cathode surface occur in several configurations with significantly different structures and reactivities. In particular, we find that near the opencircuit potential, non-hydrated hydroxyl is the dominant surface species. On the basis of density functional theory calculations, we show that the removal of hydration enhances the reactivity of oxygen species. Tuning the hydration of hydroxyl near the triple phase boundary will be crucial for designing more active fuel cell cathodes.

\footnotetext{
${ }^{1}$ SUNCAT Center for Interface Science and Catalysis, SLAC National Accelerator Laboratory, 2575 Sand Hill Road, Menlo Park, California 94025, USA. 2 Joint Center for Artificial Photosynthesis (JCAP) Energy Innovation Hub, LBNL, 1 Cyclotron Road, MS 976-JCAP, Berkeley, California 94720, USA. ${ }^{3}$ SUNCAT Center for Interface Science and Catalysis, Department of Chemical Engineering, Stanford University, Stanford, California 95305, USA. ${ }^{4}$ Stanford Synchrotron Radiation Lightsource (SSRL), SLAC National Accelerator Laboratory, 2575 Sand Hill Road, Menlo Park, California 94025, USA. Correspondence and requests for materials should be addressed to H.O. (email: hirohito@slac.stanford.edu).
} 
T he performance of polymer electrolyte membrane (PEM) fuel cells is limited by the sluggish kinetics of the oxygen reduction reaction (ORR) at the platinum $(\mathrm{Pt})$ cathode. An improved understanding of catalytic steps of the ORR is thus essential for overcoming these limitations. Through electrochemical measurements, the ORR has been inferred to occur through a hydroxyl $(\mathrm{OH})$ intermediate ${ }^{1,2}$. Indeed, based on density functional theory (DFT) simulations of the oxygenated intermediates of the ORR, it has been proposed that the Pt-OH bond strength could be a key descriptor of ORR activity and could therefore guide catalyst design ${ }^{3-5}$. However, recent experiments have observed unusual ORR activity in the presence of various ions $s^{6,7}$, in dehydrated environments ${ }^{8}$ and on stepped surfaces with limited terrace widths ${ }^{9,10}$. These indicate that experiments to observe and characterize $\mathrm{OH}$ species directly during the ORR are essential.

As most in situ experimental methods cannot detect oxygenated adsorbed species, the identification of $\mathrm{OH}$ is especially challenging. For example, Pt $L$-edge X-ray absorption spectroscopy, which probes the Pt substrate ${ }^{11}$, is typically sensitive to changes in the Pt oxidation state but cannot distinguish $\mathrm{OH}$ from other oxygenated species adsorbed on the surface ${ }^{12}$. The application of vibrational spectroscopy is also limited by the strong absorbance of both the electrolyte solution and the electrolyte membrane, which makes the weak vibrational signature of the $\mathrm{OH}$ species virtually undetectable ${ }^{13,14}$. X-ray photoelectron spectroscopy (XPS), which probes all oxygenated surface species with equal sensitivity, has been used to study Pt single-crystal electrodes ${ }^{15,16}$ in ultra-high vacuum. The challenge with these ex situ measurements is to minimize decomposition and contamination during sample transfer, as surface water species on Pt all desorb above $200 \mathrm{~K}$ in ultra-high vacuum ${ }^{17}$.

Here we report in situ identification of oxygenated intermediates on a Pt cathode during the ORR using ambient pressure XPS (APXPS), which enables measurements under high gas pressures $(<100 \text { Torr })^{18,19}$. We are able to identify the oxygenated intermediates of the ORR through their specific $\mathrm{O}$ $1 s$ chemical shifts. Using XPS studies of well-defined model systems as spectroscopic references, we differentiate two types of $\mathrm{OH}$ intermediates whose population depends on cell voltage: hydrated and non-hydrated $\mathrm{OH}$. We also establish that nonhydrated $\mathrm{OH}$ is the dominant surface species on a Pt cathode during the ORR at high partial pressures of $\mathrm{O}_{2(\mathrm{~g})}$. With the assistance of DFT calculations, we show that the reduction of non-hydrated $\mathrm{OH}$ requires less overpotential than that of hydrated $\mathrm{OH}$. This indicates that tuning $\mathrm{OH}$ hydration through cathode or electrolyte design will be crucial for enhancing ORR activity.

\section{Results}

Photoelectron spectroscopy measurements. We designed a PEM fuel cell compatible with our APXPS system (Fig. 1). To date, APXPS has been applied to the study of high-temperature solidoxide fuel cells ${ }^{20}$ but not to PEM fuel cells. In Fig. $2 a$, we show the $\mathrm{O} 1 s$ spectra and potentials of the cathode before and after the introduction of 0.4 Torr of $\mathrm{O}_{2(\mathrm{~g})}$ under open-circuit conditions. The evolution of cell voltage as a function of time is further explained in Methods: Evolution of cell voltage and Supplementary Fig. S1. Anodic charging following the introduction of $\mathrm{O}_{2(\mathrm{~g})}$ causes the electrochemical potential at the cathode to increase from 0.1 to $0.9 \mathrm{~V}$. The latter voltage of $0.9 \mathrm{~V}$ represents the maximum electrochemical potential available at the cathode in our set-up; the deviation from the Nernst potential of the ORR at the 0.4 -Torr $\mathrm{O}_{2}$ pressure $(1.182 \mathrm{~V})$ is attributed to kinetic losses ${ }^{3}$. For a given potential, the spectra recorded at

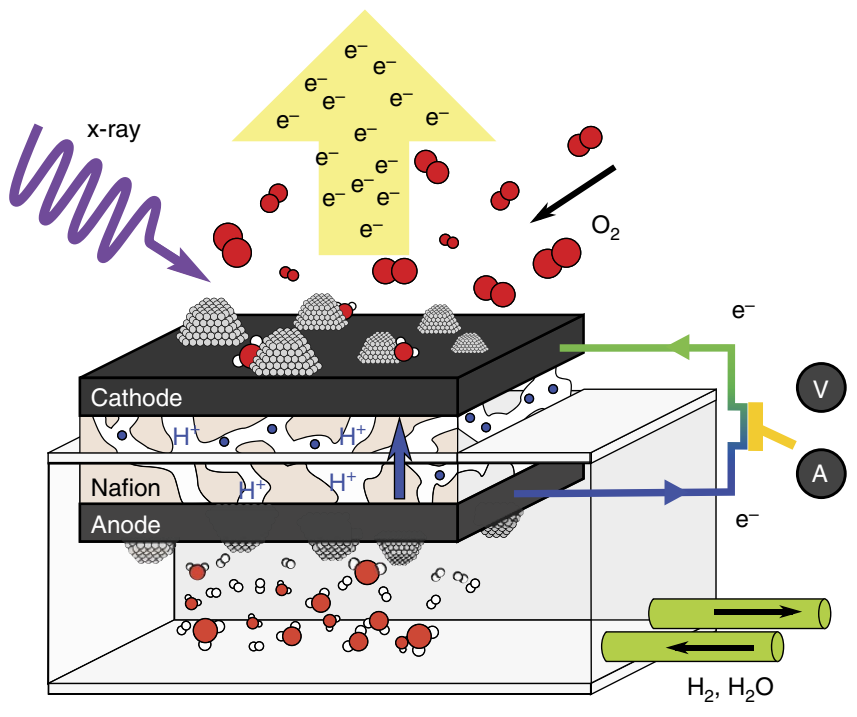

Figure 1 | Electrochemical cell for photoelectron spectroscopy. Schematic drawing of a PEM fuel cell set-up for APXPS investigations: the electrochemical cell has a Nafion membrane coated on both sides with a mixture of Nafion and carbon-supported Pt nanoparticles with catalyst loading of $4 \mathrm{mg} \mathrm{cm}^{-2}$ (particle size $10-20 \mathrm{~nm}$ ), which serve as anode and cathode. The cathode side of the assembly was exposed to the APXPS gas cell, which was filled with oxygen gas. The anode chamber was filled with humidified forming gas $\left(95 \% \mathrm{~N}_{2} / 5 \% \mathrm{H}_{2}\right.$, saturated $\mathrm{H}_{2} \mathrm{O}$ ). The voltmeter and galvanometer used for measurements are denoted by $\mathrm{V}$ and $\mathrm{A}$, respectively. By connecting both electrodes to an external voltmeter or galvanometer, we can simultaneously record both XPS and either cell voltage or cell current.

different positions on the sample do not differ strongly, which indicates that the electrochemistry is not localized but occurs throughout the surface. This suggests that only a few layers of interfacial water are needed to conduct protons across the interface; recent studies of photocatalytic water splitting reached a similar conclusion $^{21}$.

First, we establish the relationship between the electrochemical potential and surface species at the cathode. Both the electrochemical potential and the work function of a surface describe how strongly it binds electrons. It has been demonstrated that shifts in the XPS-binding energies (BE) of gaseous molecules, when referenced to the Fermi level in the vicinity of the surface $e^{20,22}$, can be used to determine changes in the work function; accordingly, changes in the electrochemical potential can be inferred from XPS. Guided by that principle, we measured the O $1 s$ XPS spectra of oxygen molecules in the vicinity of the cathode (Fig. 2b). From the shifts in the gas-phase peak, we were able to correlate changes in the work function with those in the cathode electrochemical potential (Fig. 2c). As these two sets of shifts closely agree, the observed changes in electrochemical potential at the cathode must arise from changes in surface speciation.

To understand the relationship between electrochemical potential and surface species at the cathode, we compared our results with previously assigned XPS features of various oxygenated adsorbates on $\mathrm{Pt}$. We compare our results to $\mathrm{Pt}(111)$, as our system contains nanoparticles $10-20 \mathrm{~nm}$ in size (see Methods) the close-packed terrace sites will dominate ${ }^{23}$. In Fig. 2d,e, we display $\mathrm{O} 1 s$ spectra and corresponding schematic illustrations for four oxygenated adsorbate systems on $\mathrm{Pt}(111)$ : multilayer $\mathrm{H}_{2} \mathrm{O}^{24}$; adsorbed $\mathrm{H}_{2} \mathrm{O} \quad\left(\mathrm{H}_{2} \mathrm{O}_{(\mathrm{ad})}\right)^{24}$; co-adsorbed $\mathrm{H}_{2} \mathrm{O}$ and $\mathrm{OH}\left(\mathrm{H}_{2} \mathrm{O}-\mathrm{OH}\right)^{25}$; co-adsorbed $\mathrm{OH}$ and $\mathrm{O}(\mathrm{OH}-\mathrm{O})$. 
a

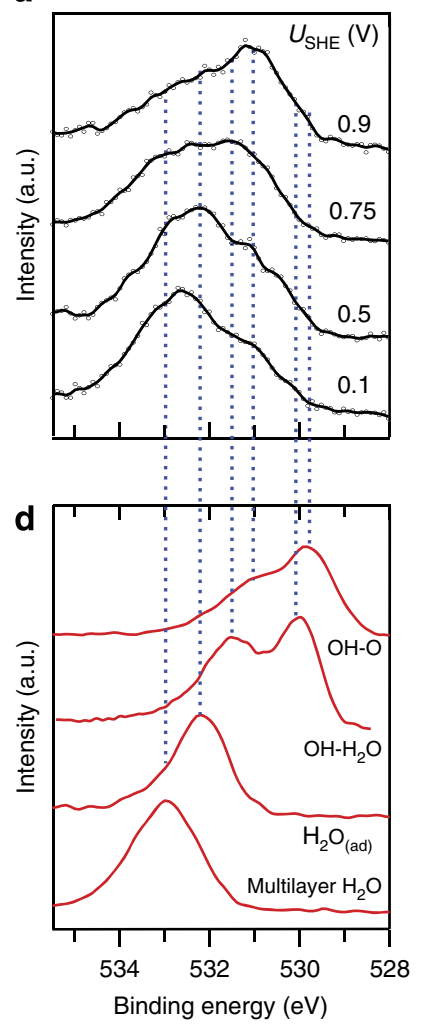

b

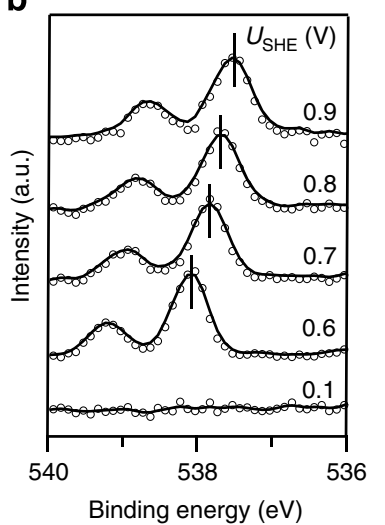

c

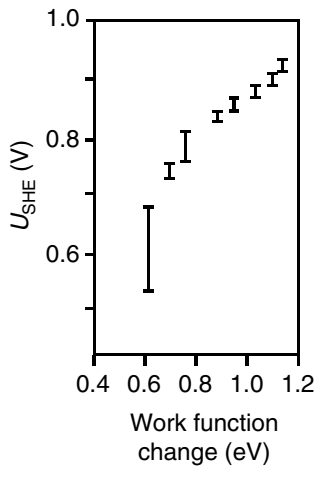

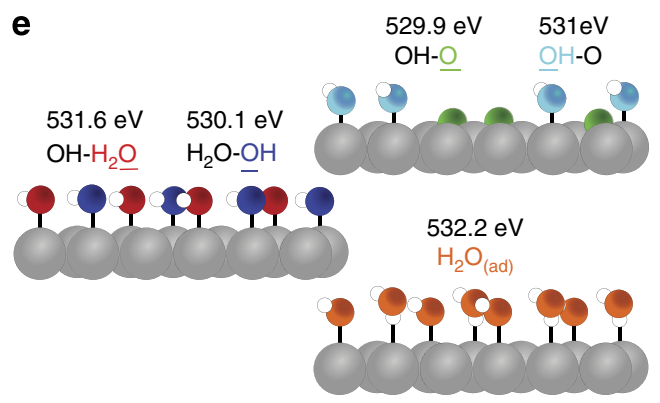

Figure 2 | Identification of oxygenated species on Pt cathode. (a) O 1s XPS spectra of a fuel cell cathode. The incident photon energy was 670 eV. Dots and solid lines correspond to experimental results and smoothened curves (first-order binomial), respectively. Spectra between 0.5 and $0.9 \mathrm{~V}$ were collected while exposing the anode to 600 Torr of humidified forming gas and the cathode to 0.4 Torr $\mathrm{O}_{2}$. The spectrum at $0.1 \mathrm{~V}$ was taken in the absence of oxygen. (b) $01 s$ XPS spectra of oxygen gas in the vicinity of the cathode. The electrochemical potential of the cathode quoted against standard hydrogen electrode (SHE), $U_{S H E}$, was measured simultaneously against the anode. The observed multiplet splitting is due to the coupling between the unpaired spins in the valence and core levels in a paramagnetic oxygen molecule ${ }^{33}$. (c) Plot of the measured cathode potential versus the change in work function. The bottom and top of bar correspond to the cathode electrochemical potential measured at the beginning and end of XPS data accumulation, respectively. (d) $\mathrm{O}$ 1s XPS spectra of oxygenated surface species on Pt(111). Bottom to top: multilayer $\mathrm{H}_{2} \mathrm{O}^{24} ; \mathrm{H}_{2} \mathrm{O}_{\text {(ad) }}{ }^{24}$; adsorbed $\mathrm{H}_{2} \mathrm{O}-\mathrm{OH}^{25}$; adsorbed $\mathrm{OH}-\mathrm{O}$ measured in 0.05 Torr $\mathrm{O}_{2}$ and 0.05 Torr $\mathrm{H}_{2}$ at $450 \mathrm{~K}$. (e) Schematic models and BE for oxygenated species: $\mathrm{H}_{2} \mathrm{O}_{\text {(ad) }}$ (orange, $532.2 \mathrm{eV}$ ),

$\mathrm{H}_{2} \underline{\mathrm{O}}-\mathrm{OH}$ (red, $531.6 \mathrm{eV}$ ), $\mathrm{H}_{2} \mathrm{O}-\underline{\mathrm{OH}}$ (blue, $530.1 \mathrm{eV}$ ), $\mathrm{O}-\underline{\mathrm{OH}}$ (cyan, $531 \mathrm{eV}$ ) and $\underline{\mathrm{O}}-\mathrm{OH}$ (green, $529.9 \mathrm{eV}$ ).

These reference spectra indicate that features at 533 and $532.2 \mathrm{eV}$ are assigned to multilayer $\mathrm{H}_{2} \mathrm{O}$ and $\mathrm{H}_{2} \mathrm{O}_{(\text {ad) }}$, respectively. The co-adsorbed $\mathrm{H}_{2} \mathrm{O}-\mathrm{OH}$ layer, in which both $\mathrm{OH}$ and $\mathrm{H}_{2} \mathrm{O}$ are hydrogen bonded to each other, yields $\mathrm{O} 1 \mathrm{~s}$ features at 531.6 and $530.1 \mathrm{eV}$ arising from adsorbed water $\left(\mathrm{H}_{2} \mathrm{O}-\mathrm{OH}\right)$ and $\mathrm{OH}\left(\mathrm{H}_{2} \mathrm{O}-\mathrm{OH}\right)$, respectively. The co-adsorbed $\mathrm{O} H-\mathrm{O}$ layer, in contrast, gives rise to an $\mathrm{OH}$ feature at $531 \mathrm{eV}(\mathrm{OH}-\mathrm{O})$ and a second feature at $529.9 \mathrm{eV}$ that is assigned to adsorbed $\mathrm{O}$ on $\mathrm{Pt}(111)^{25}(\mathrm{OH}-\mathrm{O})$; that the $\mathrm{BE}$ of $\mathrm{OH}$ is $0.9 \mathrm{eV}$ higher in $\mathrm{OH}-\mathrm{O}$ (non-hydrated $\mathrm{OH}$ ) than in $\mathrm{H}_{2} \mathrm{O}-\mathrm{OH}$ (hydrated $\mathrm{OH}$ ) is attributed to the absence of hydrogen bonding in the former phase.

Turning to Fig. 2d, with spectra measured in situ under opencircuit conditions, we see that water-related spectral features dominate at lower potentials $(0.1$ and $0.5 \mathrm{~V})$. Under these conditions, we clearly resolve a low-binding energy shoulder arising from a hydrogen-bonded network of co-adsorbed $\mathrm{OH}$ and $\mathrm{H}_{2} \mathrm{O}$ species $\left(\mathrm{H}_{2} \mathrm{O}-\mathrm{OH}\right)$. At high potentials $(0.75$ and $0.9 \mathrm{~V})$, the dominant feature at $531 \mathrm{eV}$ cannot be explained solely by hydrated $\mathrm{OH}$, even when considering the $0.3 \mathrm{eV} \mathrm{BE}$ variation due to different facets ${ }^{16}$. Thus, we assign it to non-hydrated $\mathrm{OH}$ with small contribution from $\mathrm{OH}-\underline{\mathrm{O}}$. The broadness of the spectra recorded at high potentials arises from the existence of $\mathrm{OH}$ species with differing degrees of hydration-the $\mathrm{BE}$ of $\mathrm{OH}$ ranges from $531 \mathrm{eV}$ for non-hydrated $\mathrm{OH}$ to $530.1 \mathrm{eV}$ for fully hydrated $\mathrm{OH}$-as well as from the heterogeneity of the $\mathrm{Pt}$ nanoparticles in the sample.

We now shift our focus to the role of adsorbates on the cathode when a current is extracted. Figure 3 a shows the O $1 s$ spectra of the cathode surface collected while the cell is generating current ('closed circuit' conditions). These spectra were stable under constant $\mathrm{O}_{2}$ pressure $\left(p\left(\mathrm{O}_{2}\right)\right.$, and their profiles were reversible with respect to variations of $\left(p\left(\mathrm{O}_{2}\right)\right.$. At low oxygen pressures $\left(p\left(\mathrm{O}_{2}\right)<0.15\right.$ Torr $)$, multilayer $\mathrm{H}_{2} \mathrm{O}$ and $\mathrm{H}_{2} \mathrm{O}_{(\mathrm{ad})}$ features dominate; the spectra recorded at oxygen pressures of 0 and 0.15 Torr are similar to the 0.1 and $0.5 \mathrm{~V}$ spectra shown in Fig. 2a obtained under open-circuit conditions (the elucidation of the cathode potential is described in Methods: Comparison of XPS spectra and Supplementary Fig. S2). As the $\mathrm{O}_{2}$ pressure increases $\left(p\left(\mathrm{O}_{2}\right)>0.5\right.$ Torr $)$, the current output increases and the spectra develop a major feature at a $\mathrm{BE}$ corresponding to non-hydrated $\mathrm{OH}$ species. Figure $3 \mathrm{~b}$ illustrates this point by showing a spectral deconvolution of the surface species at an oxygen pressure of 0.8 Torr. Although this spectral decomposition is not unique because of the numerous species involved and the multiple degrees of hydrogen bonding available to the $\mathrm{OH}$ species, all fits agree that the most prominent spectral feature arises from non- 
a

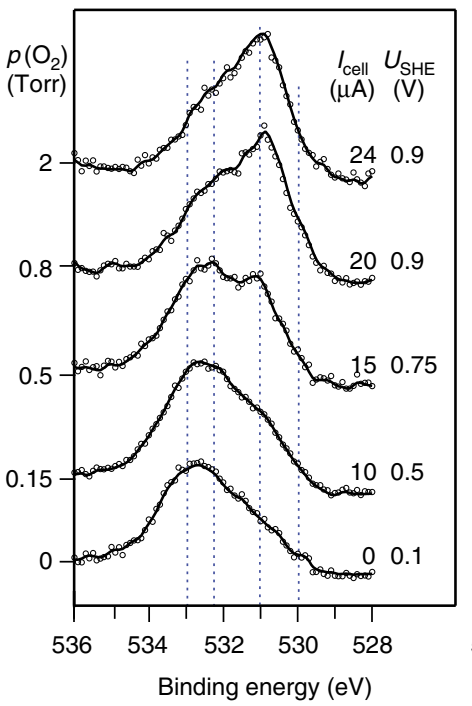

b

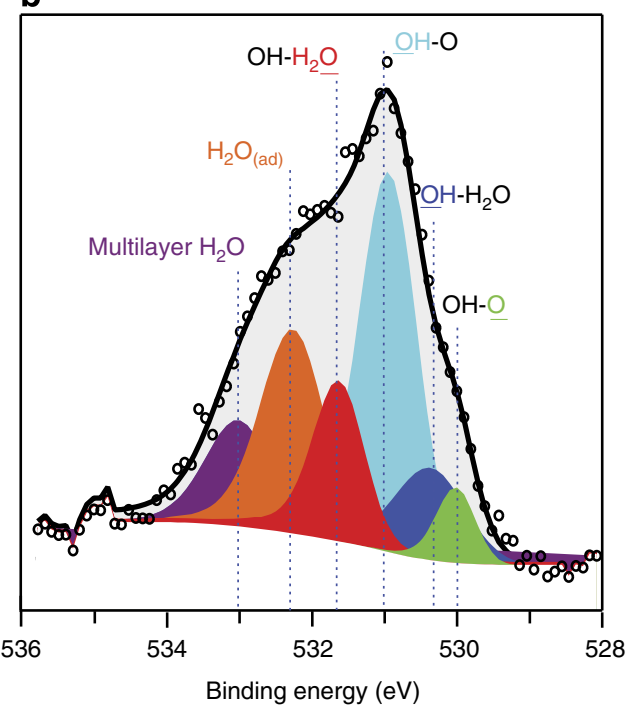

Figure 3 | XPS spectra of cathode under operating conditions. (a) O 1s XPS spectra obtained for an operating (closed circuit) fuel cell cathode. The incident photon energy was $670 \mathrm{eV}$. Spectra were collected under 600 Torr of humidified forming gas at the anode and varying $\mathrm{O}_{2}$ pressures at the cathode, as shown. The resulting current outputs, $I_{\text {cell, }}$ and the elucidated cathode potential, $U_{S H E}$ measured using XPS (see Methods: Comparison of XPS spectra and Supplementary Fig. S2) are indicated. Dots correspond to experimental results and solid lines correspond to smoothened curves (first-order binomial). The spectral changes were reversible with respect to $p\left(\mathrm{O}_{2}\right)$. The blue dotted lines correspond to the model structures on $\mathrm{Pt}(111)$ discussed in Fig. 2b. (b) Peak-fitted O 1s XPS spectrum in 0.8 Torr oxygen. The spectra were deconvoluted using Gaussian-broadened Doniach-Šunjić functions. Because of the large number of species and parameters, this peak fitting is more qualitative than quantitative in its nature, guiding the reader's eye to the different surface species: multilayer $\mathrm{H}_{2} \mathrm{O}$ (purple), $\mathrm{H}_{2} \mathrm{O}_{\text {(ad) }}$ (orange), $\mathrm{H}_{2} \underline{\mathrm{O}}-\mathrm{OH}$ (red), $\underline{\mathrm{O}}-\mathrm{O}$ (cyan), $\mathrm{H}_{2} \mathrm{O}-\underline{\mathrm{O}} \mathrm{H}$ (blue) and $\mathrm{OH}-\underline{\mathrm{O}}$ (green).

hydrated $\mathrm{OH}$. These results clearly identify that non-hydrated $\mathrm{OH}$ species is a key surface species of ORR.

Theoretical simulations. Using DFT and Monte Carlo simulations, we have calculated the coverages of adsorbed water $\left(\mathrm{H}_{2} \mathrm{O}_{(\mathrm{ad})}\right), \mathrm{OH}\left(\mathrm{OH}_{(\mathrm{ad})}\right)$ and $\mathrm{O}\left(\mathrm{O}_{(\mathrm{ad})}\right)$ as a function of computed electrochemical potential (Fig. $4 \mathrm{a}$ ). We emphasize that the coverages are averaged quantities. At low potentials, below $0.65 \mathrm{~V}$, $\mathrm{H}_{2} \mathrm{O}_{(\mathrm{ad})}$ is the dominant species. Above $0.65 \mathrm{~V}, \mathrm{OH}_{(\mathrm{ad})}$ begins to appear from the oxidation of $\mathrm{H}_{2} \mathrm{O}_{(\mathrm{ad})}$. Passing the reversible potential of this reaction at $0.76 \mathrm{~V}$ (ref. 26), the coverage of $\mathrm{OH}$ $\left(\theta\left(\mathrm{OH}_{(\mathrm{ad})}\right)\right.$ becomes greater than that of $\mathrm{H}_{2} \mathrm{O}_{(\mathrm{ad})}\left(\theta\left(\mathrm{H}_{2} \mathrm{O}_{(\mathrm{ad})}\right)\right.$. Higher potentials lead to further oxidation of $\mathrm{OH}_{(\mathrm{ad})}$ into $\mathrm{O}_{(\mathrm{ad})}$, which becomes the dominant surface species at potentials above the reversible potential of $0.95 \mathrm{~V}$ (ref. 26). Representative snapshots of the adsorbate layer at two different potentials $(0.8$ and $0.95 \mathrm{~V}$ ) are shown in Fig. $4 \mathrm{~b}$. First, we find that at $0.8 \mathrm{~V}$, all $\mathrm{OH}_{(\mathrm{ad})}$ have hydrogen bonds to $\mathrm{H}_{2} \mathrm{O}_{(\mathrm{ad})}$ indicating only hydrated $\mathrm{OH}$ is present on the surface. On the other hand, we find $\mathrm{OH}_{(\mathrm{ad})}$ both with and without hydrogen bonds to $\mathrm{H}_{2} \mathrm{O}_{(\mathrm{ad})}$ at $0.95 \mathrm{~V}$. This is consistent with the XPS results (Fig. 2a), which show that adsorbed water and hydrated $\mathrm{OH}$ prevail at low potentials, whereas non-hydrated $\mathrm{OH}$ appears at high potentials. The emergence of $\mathrm{OH}_{(\mathrm{ad})}$ without hydrogen bond is correlated with the appearance of $\mathrm{O}_{(\mathrm{ad})}$-rich domains, which displace $\mathrm{H}_{2} \mathrm{O}_{(\mathrm{ad})}$ because of repulsive interactions between $\mathrm{O}_{(\mathrm{ad})}$ and $\mathrm{H}_{2} \mathrm{O}_{(\mathrm{ad})}$. Through this insight, we explain that the hydrated and nonhydrated $\mathrm{OH}$ observed in Fig. $3 \mathrm{~b}$ co-exist in localized domains.

\section{Discussion}

Our studies not only confirm the presence of $\mathrm{OH}_{(\mathrm{ad})}$ during ORR conditions but, most importantly, also demonstrate that there are two phases of $\mathrm{OH}$, hydrated $\mathrm{OH}$ and non-hydrated $\mathrm{OH}$, coexisting under operating conditions. This distinction led us to evaluate their reactivity for the reduction of oxygen by constructing a free-energy diagram at a potential of $0.9 \mathrm{~V}$ based on DFT calculations (Fig. 4c). In the hydrated pathway, the limiting step is associated with the removal of $\mathrm{OH}_{(\mathrm{ad})}$ on $\mathrm{Pt}(111)$. In the non-hydrated pathway, the removal of hydration enhances the reactivity of $\mathrm{OH}_{(\mathrm{ad})}$ but creates a thermodynamic barrier to the activation of $\mathrm{O}_{2(\mathrm{~g})}$ as adsorbed $\mathrm{OOH}\left(\mathrm{OOH}_{(\mathrm{ad})}\right)$ because of a combination of weakening interactions from dehydration and repulsive adsorbate-adsorbate interactions with $\mathrm{O}_{(\mathrm{ad})}$. Therefore, at $0.9 \mathrm{~V}$, the thermodynamic barrier associated with the overall ORR process is $0.07 \mathrm{eV}$ in the non-hydrated pathway, corresponding to the conversion of $\mathrm{O}_{2(\mathrm{~g})}$ to $\mathrm{OOH}_{(\mathrm{ad})}$. On the other hand, in the hydrated pathway, this barrier becomes $0.15 \mathrm{eV}$ for the removal of hydrated $\mathrm{OH}_{(\mathrm{ad})}$. This analysis suggests that extending the stability range of the non-hydrated phase will prove beneficial in improving the overall ORR activity.

The importance of non-hydrated $\mathrm{OH}$ for the ORR at high potentials explains the enhanced ORR activity of $\mathrm{Pt}$ in hydrophobic ionic liquids ${ }^{8}$, in the presence of certain aqueous ions $^{6,7}$ and on stepped surfaces with narrow terrace width ${ }^{9,10}$. The last is unexpected as step sites strongly bind $\mathrm{OH}$, as indeed observed with a reduced activity for small $\mathrm{Pt}$ nanoparticles ${ }^{27}$. However, whereas adsorbed $\mathrm{H}_{2} \mathrm{O}$ and $\mathrm{OH}$ form an extended hydrogen-bonding network on wide terraces ${ }^{25}$, that process is hindered on narrow terraces because of limited space and thus the amount of non-hydrated $\mathrm{OH}$ is increased. In general, dehydrated environments ${ }^{8}$ will by their very nature limit the hydration of any $\mathrm{OH}$ intermediates. Finally, as hydrogen bonding of $\mathrm{H}_{2} \mathrm{O}$ to $\mathrm{OH}$ can compete with direct ion-OH interactions ${ }^{28}$, specific ions in the electrolyte could limit the hydration of $\mathrm{OH}^{6,7}$. This new insight into the subtle interplay between non-covalent hydrophobic and hydrophilic interactions can inspire the design of new catalysts, not only for the ORR but also for other relevant electrochemical reactions. 
a

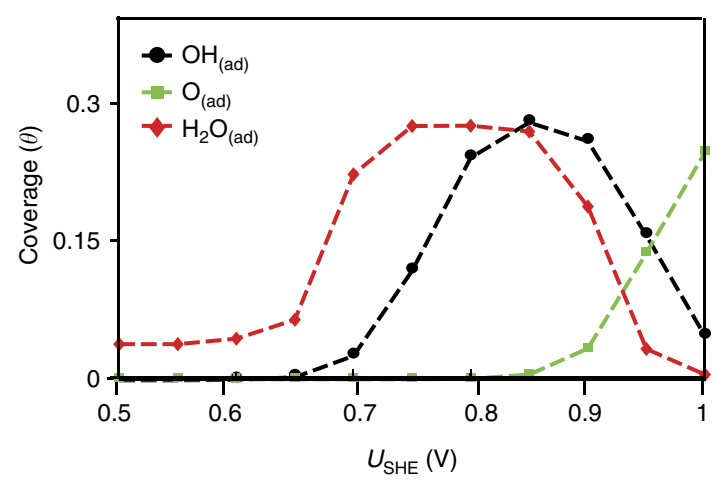

b

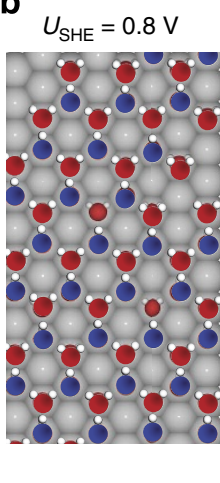

$U_{\mathrm{SHE}}=0.95 \mathrm{~V}$

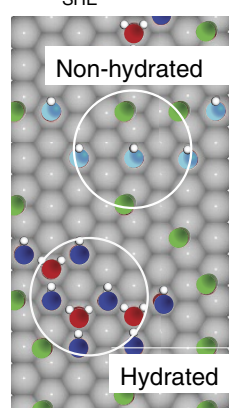

c

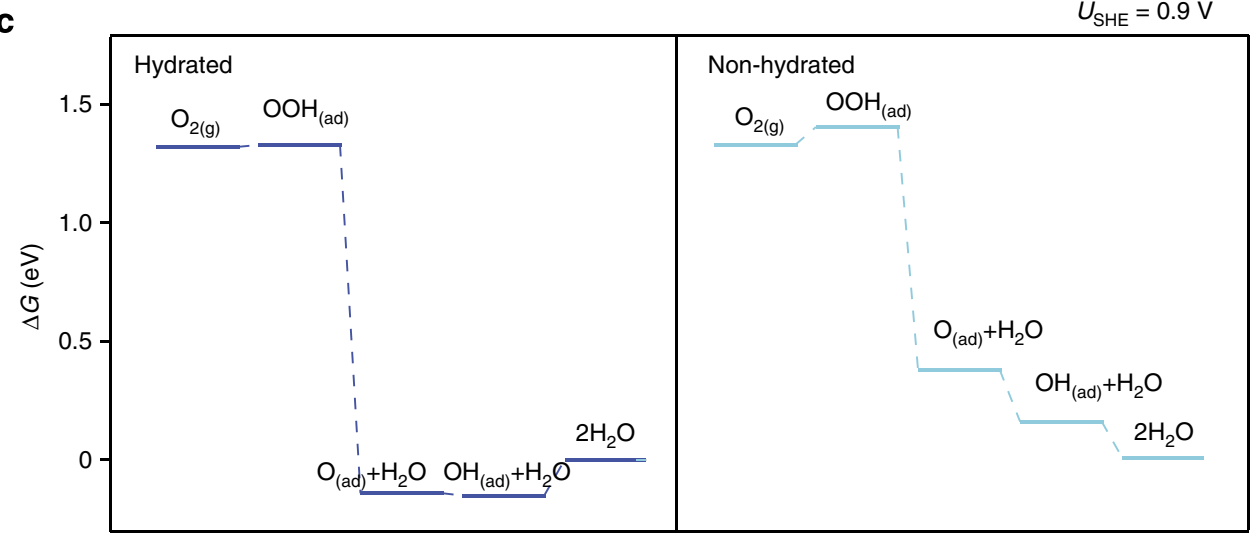

Reaction coordinate

Figure 4 | DFT and Monte Carlo simulations. (a) Calculated coverages of adsorbed oxygen, $\mathrm{OH}$ and water as a function of computed electrochemical potential, $U_{S H E}$ obtained from DFT and Monte Carlo simulations. The regions marked are separated by the emergence of $\mathrm{O}_{(\mathrm{ad})}$ at $0.85 \mathrm{~V}$. (b) Representative snapshots of the surface at 0.8 and $0.95 \mathrm{~V}$ from the Monte Carlo simulations exemplify the two regimes shown in $\mathbf{a}$, with $\mathrm{H}_{2} \mathrm{O}_{\text {(ad) }}$ ( $(\mathrm{red}$ and white circles), hydrated $\mathrm{OH}_{(\mathrm{ad})}$ (blue and white circles), non-hydrated $\mathrm{OH}_{(\mathrm{ad})}$ (cyan and white circles) and $\mathrm{O}_{(\mathrm{ad})}$ (green circles) shown on a Pt (grey circles) surface. The adsorbate layer between 0.85 and $1 \mathrm{~V}$ consists of co-existing localized domains of both hydrated and non-hydrated $\mathrm{OH}$, which we have marked in the corresponding schematic. (c) Free-energy diagrams for the ORR, based on DFT calculations for both hydrated and non-hydrated pathways, at a potential of $U_{\mathrm{SHE}}=0.9 \mathrm{~V}$. The change in Gibbs free energy, $\Delta G$, along the reaction coordinate shows that the thermodynamically limiting step in the hydrated phase is the removal of adsorbed $\mathrm{OH}$. In the non-hydrated phase, the limiting step is the activation of $\mathrm{O}_{2}$ as $\mathrm{OOH}_{(\mathrm{ad})}$.

\section{Methods}

Experimental details. The electrochemical cell assembled on a polyetheretherketone (PEEK) polymer framework has a Nafion 115 membrane coated on both sides with Pt nanoparticles, which serve as anode and cathode, supported on a Nafion/carbon-black mixture with catalyst loading of $4 \mathrm{mg} \mathrm{cm}^{-2}$ from the Fuel Cell Store, Inc (Boulder, CO; particle size 10-20 nm). The cathode was exposed to the APXPS gas cell, which was filled with oxygen gas. The anode chamber was filled with humidified forming gas $\left(95 \% \mathrm{~N}_{2} / 5 \% \mathrm{H}_{2}\right)$ to provide hydrogen fuel and membrane humidification. For open-circuit measurements, the anode was used as a hydrogen electrode. All reported potentials are referenced to the standard hydrogen electrode. Using the Nernst equation, $-\frac{2 F}{R T} \ln \left(\frac{p\left(H_{2}\right)}{p_{0}}\right)$, the anode potential is calculated to be $0.065 \mathrm{~V}$ against standard hydrogen electrode. Here $F$ is the Faraday constant, $R$ is the universal gas constant, $T$ is the temperature, $p\left(\mathrm{H}_{2}\right)$ is the partial pressure of hydrogen in the anode chamber and $p_{0}$ is the standard pressure.

The XPS measurements were performed by placing the electrochemical cell into the gas cell of the APXPS system on beamline 13-2 at the Stanford Synchrotron Radiation Lightsource ${ }^{19}$. Water vapour and hydrogen were introduced through small tubes while the cathode side exposed in the gas cell was pressurized via variable leak valves. The XPS BE is referenced to the Fermi level through measurements of the valence band under the corresponding experimental conditions. Supplementary Figure S3 shows an overview XPS spectrum of the cathode surface together with inserts showing the detailed F $1 s$ and C $1 s$ spectra before and after the introduction of oxygen to the cathode. In addition to Pt and adsorbed oxygenated species, there are spectral features from water and fluorinated carbon in Nafion binder and carbon black. The sulphur spectral contributions from the Nafion region are small compared with the carbon-black region ruling out the involvement of sulphur-containing oxygenated species in the spectral changes. To rule out the contributions of either polymer or oxidized carbon black in the $\mathrm{O} 1 \mathrm{~s}$ spectra, we show the $\mathrm{C} 1 s$ and $\mathrm{F} 1 s$ XPS before and after the introduction of oxygen as the inset of Supplementary Fig. S3, which indicate no increase of oxidized carbon- or fluorine-containing species.

Evolution of cell voltage. Supplementary Figure S1 shows the evolution of the cathode potential as a function of time under the open-circuit potential conditions in which the O 1s XPS spectra shown in Fig. 2a were collected. The anode was supplied with 600 Torr of humidified forming gas, which also humidified the cathode through the diffusion of water across the Nafion membrane. At time $t=0 \mathrm{~min}$, we introduced 0.4 Torr of oxygen gas to the cathode chamber. After the introduction of the oxygen, the cathode potential increased, eventually maintaining a constant value of $\sim 0.9 \mathrm{~V}$. The development of cell voltage correlates well with the $\mathrm{O} 1 s$ changes in XPS of the cathode, as illustrated in the accompanying spectra $(t=5,12,130$ and $177 \mathrm{~min}$ are also shown in Fig. 2a). We note that no spectral change was observed after the cell potential reaches the constant value of $0.9 \mathrm{~V}$.

Comparison of XPS spectra. Supplementary Figure S2 compares the O 1s XPS spectra shown in Fig. 3a measured under closed-circuit conditions and the $\mathrm{O} 1 \mathrm{~s}$ XPS spectra shown in Fig. 2a measured under open-circuit conditions. The cathode operating at $\mathrm{O}_{2}$ pressure of 0.15 Torr exhibits the same surface species as a cathode at an open-circuit potential of $0.1-0.5 \mathrm{~V}$. On the other end, on the cathode at $\mathrm{O}_{2}$ pressure above 0.8 Torr exhibits the same surface species as those observed at an open-circuit potential of $0.9 \mathrm{~V}$. We used this information to elucidate the cathode potential under closed-circuit reaction conditions.

Computational details. The simulation of the reaction kinetics is accomplished through a combination of equilibrium and dynamic Monte Carlo methods using kinetic and thermodynamic parameters calculated from DFT. The DFT 
calculations were performed using the DACAPO and ASE codes (https://www.wiki. fysik.dtu.dk). The ionic cores were described using ultrasoft pseudopotentials ${ }^{29}$ and the Kohn-Sham one-electron states were expanded using plane waves with kinetic energies below $340 \mathrm{eV}$. The density was expanded using plane waves with a cutoff corresponding to $500 \mathrm{eV}$ and the first Brillouin zone was sampled using a $4 \times 4 \times 1$ mesh of Monkhorst-Pack $k$-points ${ }^{30}$. The Hamiltonian was corrected for the electrostatic dipole interaction between periodically repeated slabs ${ }^{31}$. A lattice-gas model was employed in the Monte Carlo simulations, which treats the hydrogen bonding between different water species, $\mathrm{OH}$ and $\mathrm{O}$. The interaction energies between various species are summarized in Supplementary Table S1. A full description of the methodology is given in ref. 26.

The free-energy diagram for the reduction of $\mathrm{O}_{2}$ to $\mathrm{H}_{2} \mathrm{O}$ in the hydrated environment is based on DFT calculations from ref. 32. The free-energy diagram for $\mathrm{O}_{2}$ reduction in the O-rich non-hydrated environment is calculated based on DFT calculations by combining corrections to the adsorbate due to the $\mathrm{H}_{2} \mathrm{O}$ and $\mathrm{O}$ environment separately as described below.

The free-energy non-hydrated $\mathrm{OH}$ is derived from a $0.26 \mathrm{eV}$ destabilization of $\mathrm{OH}$ based on differences in $\mathrm{OH}-\mathrm{H}_{2} \mathrm{O}$ interactions in hydrated and non-hydrated environments ${ }^{26}$. In addition, a $0.04 \mathrm{eV}$ destabilization of $\mathrm{OH}$ adsorbed on top is found for $\mathrm{OH}$ co-adsorbed with $1 / 4$ monolayer (ML) of $\mathrm{O}$. The free energy of $\mathrm{O}$ in the non-hydrated environment is calculated from a $0.51-\mathrm{eV}$ destabilization of $\mathrm{O}$ with $1 / 4 \mathrm{ML}$ of $\mathrm{O}$ co-adsorbed. The interaction between $\mathrm{O}$ and $\mathrm{H}_{2} \mathrm{O}$ is weak ${ }^{3}$ and differences in $\mathrm{H}_{2} \mathrm{O}-\mathrm{O}$ interactions have been neglected for the free energy of $\mathrm{O}$. The free energy of $\mathrm{OOH}$ is obtained from a $0.05 \mathrm{eV}$ destabilization from 1/4 ML of $\mathrm{O}$ and a $0.02 \mathrm{eV}$ destabilization of $\mathrm{OOH}$ in a pure $\mathrm{H}_{2} \mathrm{O}$ environment compared with an $\mathrm{OH} / \mathrm{H}_{2} \mathrm{O}$ environment.

The calculation of the interactions between $\mathrm{O}$ and $\mathrm{OOH}, \mathrm{O}$ and $\mathrm{O}, \mathrm{OH}$ and $\mathrm{O}$ and the water stabilization of $\mathrm{OOH}$ are all performed in a $(2 \sqrt{3} \times 2 \sqrt{3})$ surface unit cell. All computational cells contained four $\mathrm{Pt}(111)$ layers where the bottom two layers are fixed in their bulk positions. The geometry of the two topmost Pt layers and adsorbates is optimized until the largest force component is below $0.03 \mathrm{eV}^{-1}$.

The electrochemical potentials were calculated using the computational hydrogen electrode method ${ }^{3}$.

\section{References}

1. Marković, N. M. \& Ross, Jr P. N. Surface science studies of model fuel cell electrocatalysts. Surf. Sci. Rep. 45, 117-229 (2002).

2. Bondarenko, A. S. et al. The $\mathrm{Pt}(111) /$ electrolyte interface under oxygen reduction reaction conditions: an electrochemical impedance spectroscopy study. Langmuir 27, 2058-2066 (2011).

3. Nørskov, J. K. et al. Origin of the overpotential for oxygen reduction at a fuel-cell cathode. J. Phys. Chem. B 108, 17886-17892 (2004).

4. Viswanathan, V., Hansen, H. A., Rossmeisl, J. \& Nørskov, J. K. Universality in oxygen reduction electrocatalysis on metal surfaces. ACS Catal. 2, 1654-1660 (2012).

5. Zhang, J. et al. Mixed-metal Pt monolayer electrocatalysts for enhanced oxygen reduction kinetics. J. Am. Chem. Soc. 127, 12480-12481 (2005).

6. Strmcnik, D. et al. Enhanced electrocatalysis of the oxygen reduction reaction based on patterning of platinum surfaces with cyanide. Nat. Chem. 2, 880-885 (2010).

7. Strmcnik, D. et al. The role of non-covalent interactions in electrocatalytic fuel-cell reactions on platinum. Nat. Chem. 1, 466-472 (2009).

8. Snyder, J., Fujita, T., Chen, M. W. \& Erlebacher, J. Oxygen reduction in nanoporous metal-ionic liquid composite electrocatalysts. Nat. Mater. 9, 904-907 (2010).

9. Maciá, M. D., Campiña, J. M., Herrero, E. \& Feliu, J. M. On the kinetics of oxygen reduction on platinum stepped surfaces in acidic media. J. Electroanal. Chem. 564, 141-150 (2004).

10. Hitotsuyanagi, A., Nakamura, M. \& Hoshi, N. Structural effects on the activity for the oxygen reduction reaction on $\mathrm{n}(111)-(100)$ series of Pt: correlation with the oxide film formation. Electrochim. Acta 82, 512-516 (2012).

11. Russell, A. E. \& Rose, A. X-ray absorption spectroscopy of low temperature fuel cell catalysts. Chem. Rev. 104, 4613-4636 (2004).

12. Friebel, D. et al. Balance of nanostructure and bimetallic interactions in $\mathrm{Pt}$ model fuel cell catalysts: in situ XAS and DFT study. J. Am. Chem. Soc. 134, 9664-9671 (2012).

13. Ayato, Y., Kunimatsu, K., Osawa, M. \& Okada, T. Study of Pt electrode/nafion ionomer interface in $\mathrm{HClO}_{4}$ by in situ surface-enhanced FTIR spectroscopy. J. Electrochem. Soc. 153, A203-A209 (2006).

14. Kunimatsu, K., Yoda, T., Tryk, D. A., Uchida, H. \& Watanabe, M. In situ ATRFTIR study of oxygen reduction at the Pt/Nafion interface. Phys. Chem. Chem. Phys. 12, 621-629 (2010).

15. Wakisaka, M., Suzuki, H., Mitsui, S., Uchida, H. \& Watanabe, M. Identification and quantification of oxygen species adsorbed on $\mathrm{Pt}(111)$ single-crystal and polycrystalline Pt electrodes by photoelectron spectroscopy. Langmuir 25, 1897-1900 (2009).
16. Wakisaka, M., Udagawa, Y., Suzuki, H., Uchida, H. \& Watanabe, M. Structural effects on the surface oxidation processes at Pt single-crystal electrodes studied by X-ray photoelectron spectroscopy. Energy Environ. Sci. 4, 1662-1666 (2011).

17. Zimbitas, G., Gallagher, M. E., Darling, G. R. \& Hodgson, A. Wetting of mixed $\mathrm{OH} / \mathrm{H}_{2} \mathrm{O}$ layers on $\mathrm{Pt}(111)$. J. Chem. Phys. 128, 074701-074712 (2008).

18. Salmeron, M. \& Schlögl, R. Ambient pressure photoelectron spectroscopy: a new tool for surface science and nanotechnology. Surf. Sci. Rep. 63, 169-199 (2008).

19. Kaya, S. et al. Ambient-pressure photoelectron spectroscopy for heterogeneous catalysis and electrochemistry. Catal. Today 205, 101-105 (2013).

20. Zhang, C. et al. Measuring fundamental properties in operating solid oxide electrochemical cells by using in situ X-ray photoelectron spectroscopy. Nat. Mater. 9, 944-949 (2010).

21. Dionigi, F. et al. Gas phase photocatalytic water splitting with $\mathrm{Rh}_{2-\mathrm{y}} \mathrm{Cr}_{\mathrm{y}} \mathrm{O}_{3} / \mathrm{GaN}$ : $\mathrm{ZnO}$ in $\mu$-reactors. Energy Environ. Sci. 4, 2937-2942 (2011).

22. Bluhm, H. et al. Methanol oxidation on a copper catalyst investigated using in situ X-ray photoelectron spectroscopy. J. Phys. Chem. B 108, 14340-14347 (2004).

23. Kinoshita, K. Particle size effects for oxygen reduction on highly dispersed platinum in acid electrolytes. J. Electrochem. Soc. 137, 845-848 (1990).

24. Schiros, T. et al. The role of substrate electrons in the wetting of a metal surface. J. Chem. Phys. 132, 094701-094709 (2010).

25. Schiros, T. et al. Structure and bonding of the water-hydroxyl mixed phase on Pt(111). J. Phys. Chem. C 111, 15003-15012 (2007).

26. Viswanathan, V. et al. Simulating linear sweep voltammetry from firstprinciples: application to electrochemical oxidation of water on $\mathrm{Pt}(111)$ and $\mathrm{Pt}_{3} \mathrm{Ni}(111)$. J. Phys. Chem. C 116, 4698-4704 (2012).

27. Perez-Alonso, F. J. et al. The effect of size on the oxygen electroreduction activity of mass-selected platinum nanoparticles. Angew. Chem. Int. Ed. 51, 4641-4643 (2012).

28. Schiros, T. et al. Cooperativity in surface bonding and hydrogen bonding of water and hydroxyl at metal surfaces. J. Phys. Chem. C 114, 10240-10248 (2010).

29. Vanderbilt, D. Soft self-consistent pseudopotentials in a generalized eigenvalue formalism. Phys. Rev. B 41, 7892-7895 (1990).

30. Monkhorst, H. J. \& Pack, J. D. Special points for Brillouin-zone integrations. Phys. Rev. B 13, 5188-5192 (1976).

31. Bengtsson, L. Dipole correction for surface supercell calculations. Phys. Rev. B 59, 12301-12304 (1999).

32. Greeley, J. et al. Alloys of platinum and early transition metals as oxygen reduction electrocatalysts. Nat. Chem. 1, 552-556 (2009).

33. Larsson, M. et al. X-ray photoelectron, Auger electron and ion fragment spectra of $\mathrm{O}_{2}$ and potential curves of $\mathrm{O}_{2}^{2+}$. J. Phys. B 23, 1175-1195 (1990).

\section{Acknowledgements}

The experimental work was supported by the Joint Center for Artificial Photosynthesis Award number DE-SC0004993 and the theoretical work by the US Department of Energy, Basic Energy Science through the SUNCAT Center for Interface Science and Catalysis. H.O. gratefully acknowledges the support from Precursory Research for Embryonic Science and Technology (PRESTO), Japan Science and Technology Agency (JST). Portions of this research were carried out at the Stanford Synchrotron Radiation Lightsource, a division of SLAC National Accelerator Laboratory and an Office of Science user facility operated by Stanford University for the US Department of Energy. We appreciate comments and valuable discussions with Ib Chorkendorff and Lars G.M. Pettersson.

\section{Author contributions}

H.O., J.K.N., S.K. and A.N. designed the research. H.S.C, S.K., D.J.M. and H.O. performed the experiments. V.V. and H.A.H. performed the theoretical calculations. H.O., H.S.C, S.K., D.J.M., D.F., V.V., J.K.N. and A.N. co-wrote the manuscript.

\section{Additional information}

Supplementary Information accompanies this paper at http://www.nature.com/ naturecommunications

Competing financial interests: The authors declare no competing financial interests.

Reprints and permission information is available online at http://npg.nature.com/ reprintsandpermissions/

How to cite this article: Casalongue, H. S. et al. Direct observation of the oxygenated species during oxygen reduction on a platinum fuel cell cathode. Nat. Commun. 4:2817 doi: 10.1038/ncomms3817 (2013). 